\title{
Association between microstructural white matter abnormalities and cognitive functioning in patients with type 2 diabetes mellitus: a diffusion tensor imaging study
}

\author{
Ahmed Osama' ${ }^{1}$ Tarek Hassan Khalil'², Mohamed Negm', Reda AbdEl-Razek ${ }^{1 *}$ and Hend AbouElhamd ${ }^{1}$
}

\begin{abstract}
Background: Diffusion tensor imaging (DTI) technique is important for exploring more sensitive imaging-based biomarkers in prevention and early treatment of cognitive dysfunction induced by type 2 diabetes mellitus (DM).

Objectives: To predict early cognitive dysfunction and detection of microstructural white matter changes in patients with type 2 DM by diffusion tensor imaging.

Patients and methods: A case-control study included thirty patients aged $\geq 18$ years old of both sexes with type 2 DM and 30 controls. All subjects underwent to Montreal Cognitive Assessment (MoCA) "Arabic version": to detect mild cognitive impairment (MCl) and diffusion tensor imaging study (DTI).

Results: Mild cognitive impairment is related to type 2 DM (56.7\% of diabetic group), reduced fractional anisotropy (FA) values, and elevated mean diffusivity (MD) values were related to cognitive impairment evaluated through Montreal Cognitive Assessment (MoCA) in patients with type 2 DM.

Conclusion: The integrity of the white matter measured using DTI vary in $\mathrm{MCl}$ diabetics compared with non-MCI diabetics. Such changes have major implications on the cognitive function.
\end{abstract}

Keywords: Type 2 DM, Mild cognitive impairment, Diffusion tensor imaging

\section{Introduction}

Diabetes mellitus (DM) afflicts nearly 382 million people worldwide, a number that is predicted to reach more than 592 million by the year 2035 [1]. Many studies have also raised concerns about the long-term consequences of poor glycemic control on the impairment of cognitive function [2,3]. Its effects on higher mental functions are frequently ignored because of the lack of obvious signs and the lack of standard evaluation techniques [4]. Many studies have reported a cognitive impairment in T2DM

\footnotetext{
*Correspondence: reda_abdelrazek@yahoo.com

${ }^{1}$ Department of Neurology, Suez Canal University, Ismailia, Egypt Full list of author information is available at the end of the article
}

[5]. And that type 2 diabetes is associated with around a 1.5 - to 2.5 -fold increase in dementia risk [6, 7]. Bruce et al. found that about $17 \%$ of the elderly patients with diabetes had moderate to serious impairments in everyday life tasks, $11 \%$ had a cognitive impairment [8]. This cognitive impairment can be due to cerebral white matter conditions, related to cerebrovascular lesions such as lacunar infarctions, hyperintensities of white matter (WMHs), and microstructural lesions [9, 10].

Neuroimaging with diffusion tensor imaging (DTI). It is a process for describing microstructural changes or differences with neuropathology and gives details about the quality of the white matter tracts. DTI calculates the 
fractional anisotropy [FA], which is a measure of the diffusion directionality and the mean diffusivity [MD], which is a directionally averaged measure of diffusion, $\mathrm{FA}$, and MD values vary from 0 to 1 [11].

Diffusion tensor imaging (DTI) is sensitive for measuring the development of the microstructure and integrity of white matter (WM) fiber tracts during the asymptomatic stage of $\mathrm{AD}[12,13]$. Fractional anisotropy (FA) and mean diffusivity (MD) describes fiber density, axonal diameter, and myelination in white matter (WM) based on quantitative measure of the degree of diffusion anisotropy [9]. The decreased FA and increased MD in mild cognitive impairment (MCI) are signs of the disruption of WM $[14,15]$. Thus, DTI technique is important for exploring more sensitive imaging-based biomarkers in the prevention and early treatment of cognitive dysfunction induced by type $2 \mathrm{DM}$.

\section{Aim of the work}

To estimate the frequency of early cognitive dysfunction and to detect changes in microstructural white matter in patients with type $2 \mathrm{DM}$ by means of diffusion tensor imaging.

\section{Patients and methods}

This case-control study was carried out in the Neurology Outpatient Clinic, Neurology Department and MRI unit, Diagnostic and Interventional Radiology Department of Suez Canal University Hospital, Ismailia, Egypt. Thirty adult patients aged $\geq 18$ years old of both sexes with type 2 DM were included. Patients with type $1 \mathrm{DM}$, hypertension, history of cerebrovascular accidents, and dementia were excluded. Another 30 healthy subjects matched by ages and sex were included as a control group.

All the patients and control subjects had undergone the following:

\section{History taking}

History taking includes age, type of DM, the duration of $\mathrm{DM}$, and type of treatment.

General examination and full neurological evaluation for identification of focal neurological deficit in patients.

\section{Investigations}

A fasting and post prandial blood sugar to confirm diagnosis of diabetes mellitus (FPG $\geq 126 \mathrm{mg} / \mathrm{dl}(7.0 \mathrm{mmol} /$ l), while post prandial 2-h plasma glucose $\geq 200 \mathrm{mg} / \mathrm{dl}$ (11.1 mmol/l) [16]. B-glycated hemoglobin (HbA 1c): those with HbA1c levels of $6.5 \%$ or higher have diabetes [17]. The reference ranges were good control less than 7\%; moderate control, 7-9\%; and poor control, more than $9 \%[18]$.

\section{Cognitive testing}

Montreal Cognitive Assessment scale (MoCA) [19]. All subjects underwent cognitive assessment using the Arabic translated form of Montreal Cognitive Assessment to confirm the presence of mild cognitive impairment [19]. The MoCA's original validation analysis proposed a cut-off value of $\geq 26$ out of 30 points to distinguish healthy subjects from mild cognitive impairment (MCI) [20].

\section{MR imaging protocol}

To get higher signal-to-noise ratio (SNR) and motion-free DTI, we used parallel imaging methods and single-shot spinecho echo-planar imaging (EPI). Depending on the section numbers the total time for imaging of DTI was 7-9 $\mathrm{min}$, in addition to the standard MR imaging exam time [21].

\section{Acquisition of MR images}

A 1.5-T MR unit has been used (Achieva; Philips Medical Systems, The Netherlands). T1-weighted sequences before and after paramagnetic contrast material given intravenously, T2-weighted sequences, and fluid-attenuated inversion recovery (FLAIR) sequences were acquired. Using a single-shot echo-planar image sequence with sensitivity encoding, or SENSE, parallel image scheme (reduction factor, 2), DT image data were obtained. The frame matrix was $128 \times 128$, with a $220 \times 220 \mathrm{~mm}$ field of view. Parallel to the anterior commissure - posterior commissure linewere acquired transverse sections of $2.75 \mathrm{~mm}$ thickness. A total of 50 sections, without gaps, filled the entire hemisphere and brainstem. Thirty-two separate orientations represented diffusion weighting and the $b$ value was 800 $\mathrm{mm}^{2} / \mathrm{s}$. Other parameters for the imaging were echo time $=70 \mathrm{~ms}$, repetition period $=6599-8280 \mathrm{~ms}$, number of acquisitions $=$ two [21].

\section{Data processing}

We moved the image data for the diffusion-tensor to an offline workstation (extended MR "EWS" workspace, Philips Medical Systems) which is based on the Continuous Tracking Fiber Assignment (FACT) process. Anisotropy was determined using orientation-independent fractional anisotropy (FA) and diffusion-tensor MR color maps based on the values of FA and the three vector elements were developed. Through linking voxel to voxel with the FACT algorithm, three-dimensional FA was then acquired. The fiber tracking termination threshold values for FA were less than 0.15 and for the trajectory angles between the ellipsoids greater than $27^{\circ}$ [21].

\section{Three-dimensional tract reconstruction}

We used a multi-region-of-interest (ROI) approach to recreate tracts of interest, which utilize established anatomical knowledge of tract trajectories. Tracking was carried out 
from all pixels within the brain ("brute force" approach), and tests penetrating the manually identified ROIs were allocated to the different tracts associated with the ROIs. By using multiple ROIs for a tract of interest, we used three types of operations, AND, OR, and NOT, whose preference depended on the trajectory characteristic of each tract. Both FA and MD have been calculated on the following tracts on both sides: Superior longitudinal fasciculus, inferior longitudinal fasciculus, uncinate fasciculus, corpus callosum (splenium), and corpus callosum (Genu) [21].

The study was accepted by the Ethical Committee of Suez Canal Faculty of Medicine. Prior to inclusion in the study, written, informed consent was obtained from all the participants.

\section{Statistical analysis}

Using IBM SPSS software package version 20.0, data was fed to the computer and analyzed. (Armonk, NY: Published 2016 by IBM Corp). Using number and percent, qualitative data were represented. The KolmogorovSmirnov test had been used to check distribution normality. Quantitative data were represented using the range (minimum and maximum), mean, standard deviation and median. Data were tabulated and statistically analyzed to determine the difference between the groups under study with respect to the different parameters.

\section{Descriptive statistics}

For representing both quantitative and qualitative variables, frequencies were used. Mean and standard deviation $( \pm \mathrm{SD})$ were only used for quantitative variables.

\section{Analytical statistics}

Student's $t$ tests were used to compare two means. ANOVA was used for comparing between more than two groups and followed by post hoc test (Tukey) for pair wise comparison. The chi-square test (Fisher or Monte Carlo) was used to analyze the difference between various proportions at the level of 95\%. MannWhitney test was used to compare between two groups for not normally distributed quantitative variables $p$ value indicates level of significance [22].

\section{Results}

This study included 60 subjects, 30 diabetic patients, and 30 nondiabetic subjects as a control. The age of the diabetic group ranged between 60 and 69 years with a mean $(63.57 \pm 2.8)$ and for the control group ranged between 60 and 67 years with a mean $(62.77 \pm 2.21)$. Seventeen subjects (56.7\%) are males and 13 (43.3\%) are females in diabetic group, while in control group, 19 subjects $(63.3 \%)$ are males and 11 subjects (36.7\%) are females. There is no statistically significant difference between both groups regarding age and sex (Table 1).
Table 1 Demographic data of diabetics and controls

\begin{tabular}{lllll}
\hline & $\begin{array}{l}\text { Controls } \\
(\boldsymbol{n}=\mathbf{3 0})\end{array}$ & $\begin{array}{l}\text { Diabetics } \\
(\boldsymbol{n}=\mathbf{3 0})\end{array}$ & Test of Sig. & $\mathbf{p}$ \\
\hline Age (years) & & & & \\
$\quad$ Range & $60-67$ & $60-69$ & $t=1.229$ & 0.224 \\
$\quad \begin{array}{l}\text { Mean } \pm \text { SD } \\
\text { Sex }\end{array}$ & $62.77 \pm 2.21$ & $63.57 \pm 2.80$ & & \\
Male & $19(63.3)$ & $17(56.7)$ & & \\
Female & $11(36.7)$ & $13(43.3)$ & $x^{2}=0.278$ & 0.598 \\
\hline
\end{tabular}

$t$ Student's $t$ test, $X^{2}$ chi-square test, $p p$ value for comparing between the studied groups

Mild Cognitive Impairment (MoCA score: 22-25) is highly significantly more frequent in the diabetics (56.7\%) $(p<0.01)$. The mean value of total MoCA score is highly significantly lower in diabetics $(24.87 \pm 2.01)$ than in the non-diabetics $(27.90 \pm 0.76)(p<0.01)$. Cognitive domains in MoCA scale that are mainly affected in the diabetic group are: orientation, short-term memory/delayed recall, executive functions/visuospatial, language, and attention. Abstraction and animal naming show no statistical difference between both groups (Table 2).

The mean duration of treatment among diabetic subjects is $(3.17 \pm 1.27)$ years. Ten patients $(33.3 \%)$ are treated for less than 2 years and 20 patients (66.7\%) are treated for more than 2 years. Mean values of the duration of treatment in diabetics with MCI $(2.77 \pm 1.1)$ years show no significant statistical difference than duration of treatment in diabetics without MCI $(3.47 \pm$ $1.33)$ years $(p>0.05)$. Moderate and poor glycemic control are significantly more frequent in diabetics with MCI $(p<0.01)$ (Table 3).

Table 2 Montreal Cognitive Assessment scale in diabetics and controls

\begin{tabular}{lllll}
\hline & $\begin{array}{l}\text { Controls } \\
(\boldsymbol{n}=\mathbf{3 0})\end{array}$ & $\begin{array}{l}\text { Diabetics } \\
(\boldsymbol{n}=\mathbf{3 0})\end{array}$ & Test of sig. & $\boldsymbol{p}$ \\
\hline MoCA & & & & \\
MCl (22-25) & $0(0 \%)$ & $17(56.7 \%)$ & $x^{2}=23.721^{*}$ & $<0.001^{*}$ \\
Normal $(\geq 26)$ & $30(100 \%)$ & $13(43.3 \%)$ & & \\
MoCA total score & $27.9 \pm 0.8$ & $24.9 \pm 2$ & $t=7.724^{*}$ & $<0.001^{*}$ \\
$\quad$ Orientation & $5.5 \pm 0.6$ & $4.7 \pm 0.6$ & $t=5.086^{*}$ & $<0.001^{*}$ \\
Short-term memory & $4.6 \pm 0.5$ & $3.7 \pm 0.6$ & $t=6.188^{*}$ & $<0.001^{*}$ \\
Executive & $4.5 \pm 0.5$ & $4 \pm 0.6$ & $t=3.893^{*}$ & $<0.001^{*}$ \\
Language & 3 & $2.6 \pm 0.5$ & $t=4.097^{*}$ & $<0.001^{*}$ \\
Abstraction & 2 & $2 \pm 0$ & - & - \\
Animal naming & 3 & $3 \pm 0$ & - & - \\
Attention & $5.3 \pm 0.5$ & $4.8 \pm 0.7$ & $t=2.904^{*}$ & $0.005^{*}$ \\
\hline
\end{tabular}

Data was expressed by using (mean \pm SD), $X^{2}$ chi-square test, $t$ Student's $t$ test, $p p$ value for comparing between the studied groups

*Statistically significant at $p \leq 0.05$

MoCA Montreal Cognitive Assessment scale, MCl mild cognitive impairment. 
Table 3 Relation between Montreal Cognitive Assessment scale and duration of treatment in diabetic subjects

\begin{tabular}{|c|c|c|c|c|}
\hline & \multicolumn{2}{|l|}{ MOCA } & \multirow[t]{2}{*}{ Test of sig. } & \multirow[t]{2}{*}{$p$} \\
\hline & Diabetics without MCI $(n=13)$ & Diabetics with MCI $(n=17)$ & & \\
\hline \multicolumn{5}{|c|}{ Duration of treatment(year) } \\
\hline$\leq 2$ years & $5(38.5 \%)$ & $5(29.4 \%)$ & $x^{2}=0.271$ & $\mathrm{FE}_{p}=0.705$ \\
\hline$>2$ years & $8(61.5 \%)$ & $12(70.6 \%)$ & & \\
\hline Min.-Max. & $1.5-6$ & $1-5$ & $U=74.0$ & 0.133 \\
\hline Mean \pm SD & $2.8 \pm 1.1$ & $3.5 \pm 1.3$ & & \\
\hline \multicolumn{5}{|l|}{$\mathrm{HbA1c}$} \\
\hline Good control & $0(0 \%)$ & $8(61.5 \%)$ & $x^{2}=16.467^{*}$ & $\mathrm{MC}_{p}=<0.001^{*}$ \\
\hline Moderate control & $4(30.8 \%)$ & $7(41.2 \%)$ & & \\
\hline Poor control & $1(7.7 \%)$ & 10 (58.8\%) & & \\
\hline
\end{tabular}

$x^{2}$ chi-square test, MC Monte Carlo, FE Fisher's exact, $U$ Mann-Whitney test, $p p$ value for comparing between the studied groups

* Statistically significant at $p \leq 0.05$

MoCA Montreal Cognitive Assessment scale, $M C l$ mild cognitive impairment, HbA1c glycosylated hemoglobin.

Fractional anisotropy in diabetic patients with MCI is highly significantly reduced at all selected tracts than diabetic patients without MCI and controls. Mean diffusivity in diabetic patients with MCI is highly significantly elevated at all selected tracts than diabetic patients without MCI and controls (Table 4).

Figure 1 shows the detailed tractography of the right uncinated fasciculus (UNC) in a normal subject. Figure 2 shows the detailed tractography of the right

Table 4 Fractional anisotropy and mean diffusivity of controls, diabetics without mild cognitive impairment, and diabetics with mild cognitive impairment

\begin{tabular}{|c|c|c|c|c|c|c|c|c|c|}
\hline & & \multirow{2}{*}{$\begin{array}{l}\text { Control } \\
n=30)\end{array}$} & \multicolumn{2}{|l|}{ Diabetics } & \multirow[t]{2}{*}{$F$} & \multirow[t]{2}{*}{$p$} & \multirow[t]{2}{*}{$p_{1}$} & \multirow[t]{2}{*}{$p_{2}$} & \multirow[t]{2}{*}{$p_{3}$} \\
\hline & & & Without $\mathrm{MCl}(n=13)$ & With $\mathrm{MCl}(n=17)$ & & & & & \\
\hline \multirow[t]{2}{*}{$\overline{S L F F A}$} & Right & $0.48 \pm 0.04$ & $0.46 \pm .047$ & $0.40 \pm .073$ & $12.394^{*}$ & $<0.001^{*}$ & 0.673 & $<0.001^{*}$ & $0.005^{*}$ \\
\hline & Left & $0.47 \pm 0.03$ & $0.44 \pm 0.04$ & $0.38 \pm 0.07$ & $20.329^{*}$ & $<0.001^{*}$ & 0.147 & $<0.001^{*}$ & $0.002^{*}$ \\
\hline \multirow[t]{2}{*}{ ILF FA } & Right & $0.39 \pm 0.05$ & $0.48 \pm 0.10$ & $0.37 \pm 0.04$ & $12.293^{*}$ & $<0.001^{*}$ & $<0.001^{*}$ & 0.442 & $<0.001^{*}$ \\
\hline & Left & $0.4 \pm \pm 0.03$ & $0.48 \pm 0.10$ & $0.33 \pm 0.04$ & $28.890^{*}$ & $<0.001^{*}$ & $<0.001^{*}$ & $<0.001^{*}$ & $<0.001^{*}$ \\
\hline \multirow[t]{2}{*}{ UNC FA } & Right & $0.43 \pm 0.04$ & $0.48 \pm 0.12$ & $0.39 \pm 0.05$ & $7.837^{*}$ & $0.001^{*}$ & $0.034^{*}$ & 0.121 & $0.001^{*}$ \\
\hline & Left & $0.42 \pm 0.04$ & $0.47 \pm 0.10$ & $0.34 \pm 0.04$ & $19.967^{*}$ & $<0.001^{*}$ & 0.091 & $<0.001^{*}$ & $<0.001^{*}$ \\
\hline \multirow[t]{2}{*}{ CCS FA } & Right & $0.44 \pm 0.08$ & $0.50 \pm 0.08$ & $0.38 \pm 0.04$ & $11.778^{*}$ & $<0.001^{*}$ & $0.018^{*}$ & $0.019^{*}$ & $<0.001^{*}$ \\
\hline & Left & $0.41 \pm 0.02$ & $0.47 \pm 0.11$ & $0.33 \pm 0.03$ & $25.579^{*}$ & $<0.001^{*}$ & $0.004^{*}$ & $<0.001^{*}$ & $<0.001^{*}$ \\
\hline \multirow[t]{2}{*}{ CCG FA } & Right & $0.40 \pm 0$ & $0.48 \pm 0.10$ & $0.38 \pm 0.04$ & $15.194^{*}$ & $<0.001^{*}$ & $<0.001^{*}$ & 0.563 & $<0.001^{*}$ \\
\hline & Left & $0.44 \pm 0.02$ & $0.47 \pm 0.11$ & $0.34 \pm 0.04$ & $27.118^{*}$ & $<0.001^{*}$ & 0.186 & $<0.001^{*}$ & $<0.001^{*}$ \\
\hline \multirow[t]{2}{*}{ SLF MD } & Right & $0.70 \pm 0.07$ & $0.72 \pm 0.10$ & $0.79 \pm 0.07$ & $6.440^{*}$ & $0.003^{*}$ & 0.947 & $0.003^{*}$ & $0.033^{*}$ \\
\hline & Left & $0.7 \pm \pm 0.08$ & $0.73 \pm 0.03$ & $0.83 \pm 0.08$ & $15.162^{*}$ & $0.001^{*}$ & 0.582 & $0.001^{*}$ & $0.002^{*}$ \\
\hline \multirow[t]{2}{*}{ ILF MD } & Right & $0.74 \pm 0.03$ & $0.71 \pm 0.07$ & $0.80 \pm 0.04$ & $16.340^{*}$ & $<0.001^{*}$ & 0.205 & $<0.001^{*}$ & $<0.001^{*}$ \\
\hline & Left & $0.75 \pm 0.03$ & $0.73 \pm 0.09$ & $0.84 \pm 0.05$ & $20.460^{*}$ & $<0.001^{*}$ & 0.294 & $<0.001^{*}$ & $<0.001^{*}$ \\
\hline \multirow[t]{2}{*}{ UNC MD } & Right & $0.75 \pm 0.03$ & $0.70 \pm 0.07$ & $0.79 \pm 0.06$ & $15.219^{*}$ & $<0.001^{*}$ & $0.005^{*}$ & $0.008^{*}$ & $<0.001^{*}$ \\
\hline & Left & $0.75 \pm 0.03$ & $0.72 \pm 0.08$ & $0.83 \pm 0.05$ & $19.609^{*}$ & $<0.001^{*}$ & 0.161 & $<0.001^{*}$ & $<0.001^{*}$ \\
\hline \multirow[t]{2}{*}{ CCS MD } & Right & $0.76 \pm 0.03$ & $0.71 \pm 0.06$ & $0.79 \pm 0.05$ & $13.308^{*}$ & $<0.001^{*}$ & $0.003^{*}$ & $0.042^{*}$ & $<0.001^{*}$ \\
\hline & Left & $0.77 \pm 0.03$ & $0.72 \pm 0.06$ & $0.82 \pm 0.05$ & $22.582^{*}$ & $<0.001^{*}$ & $0.001^{*}$ & $<0.001^{*}$ & $<0.001^{*}$ \\
\hline \multirow[t]{2}{*}{ CCG MD } & Right & $0.76 \pm 0.03$ & $0.73 \pm 0.04$ & $0.79 \pm 0.06$ & $7.537^{*}$ & $0.001^{*}$ & 0.065 & 0.080 & $0.001^{*}$ \\
\hline & Left & $0.74 \pm 0.03$ & $0.74 \pm 0.05$ & $0.82 \pm 0.06$ & $24.996^{*}$ & $<0.001^{*}$ & 0.848 & $<0.001^{*}$ & $<0.001^{*}$ \\
\hline
\end{tabular}

Data was expressed by using (mean $\pm \mathrm{SD}$ ), $\mathrm{MCl}$ mild cognitive impairment, $F F$ for ANOVA test, pair wise comparison between each 2 groups was done using post hoc test (Tukey)

$p_{1} p$ value for comparing between control and diabetics without $\mathrm{MCl}$

$p_{2} p$ value for comparing between control and diabetics with $\mathrm{MCl}$

$p_{3} p$ value for comparing between diabetics without $\mathrm{MCl}$ and diabetics with $\mathrm{MCl}$

* Statistically significant at $p \leq 0.05$

UNC Uncinate, SLF superior longitudinal fasciculus, ILF inferior longitudinal fasciculus, CCS corpus callosum splenium, CCG corpus callosum genu, FA

fractional anisotropy, $M D$ mean diffusivity 


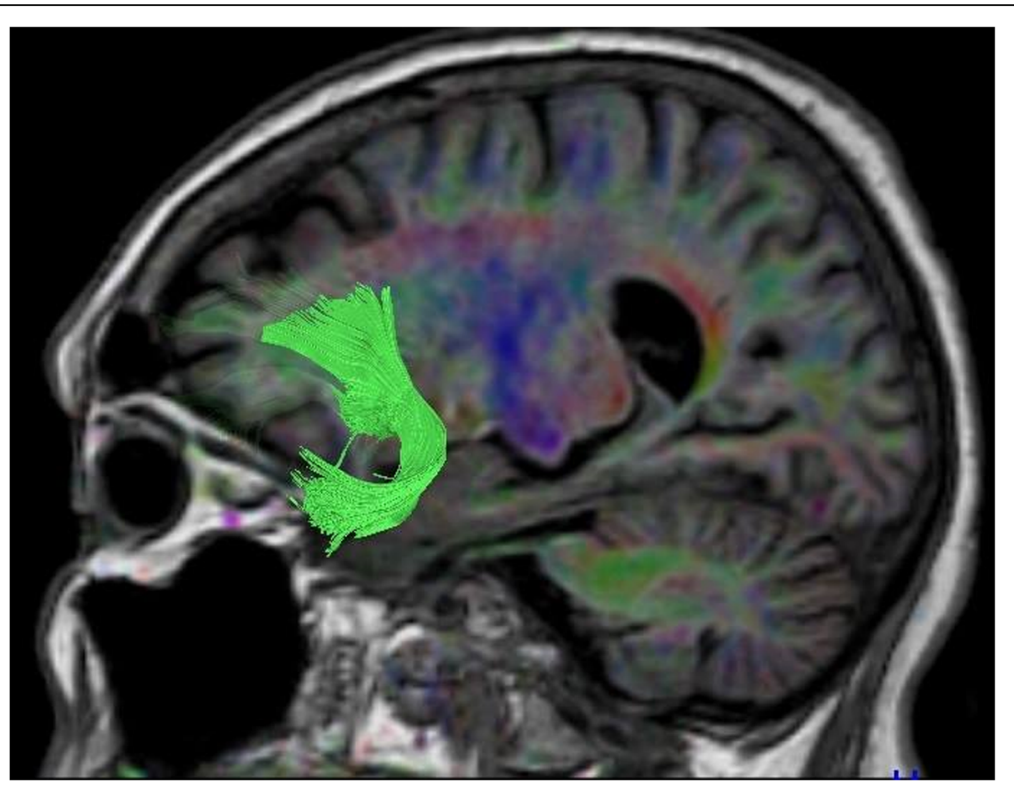

Fig. 1 Sagittal view of the detailed tractography of the right uncinated fasciculus (UNC) in a normal subject. Color coding is included to assist with identification of the fibers in the images. Fractional anisotropy (FA) and mean diffusivity (MD) are $(0.50 \pm 0.140)$ and $(0.61 \pm$ $0.198)$ respectively

superior longitudinal fasciculus (SLF) in a diabetic subject with mild cognitive impairment.

Fractional anisotropy in diabetic patients with MCI is highly significantly reduced at all selected tracts (except SLF) at left hemisphere than that at right hemisphere. Mean diffusivity in diabetic patients with MCI is highly significantly elevated at all selected tracts at left hemisphere than at right hemisphere (Table 5).
There was no significant statistical difference between fractional anisotropy and mean diffusivity and duration of treatment in diabetics at all selected tracts at left and right hemispheres (Table 6).

There was significant statistical difference between fractional anisotropy and mean diffusivity and glycemic control in diabetics at all selected tracts at left and right hemispheres except SLF (Table 7).

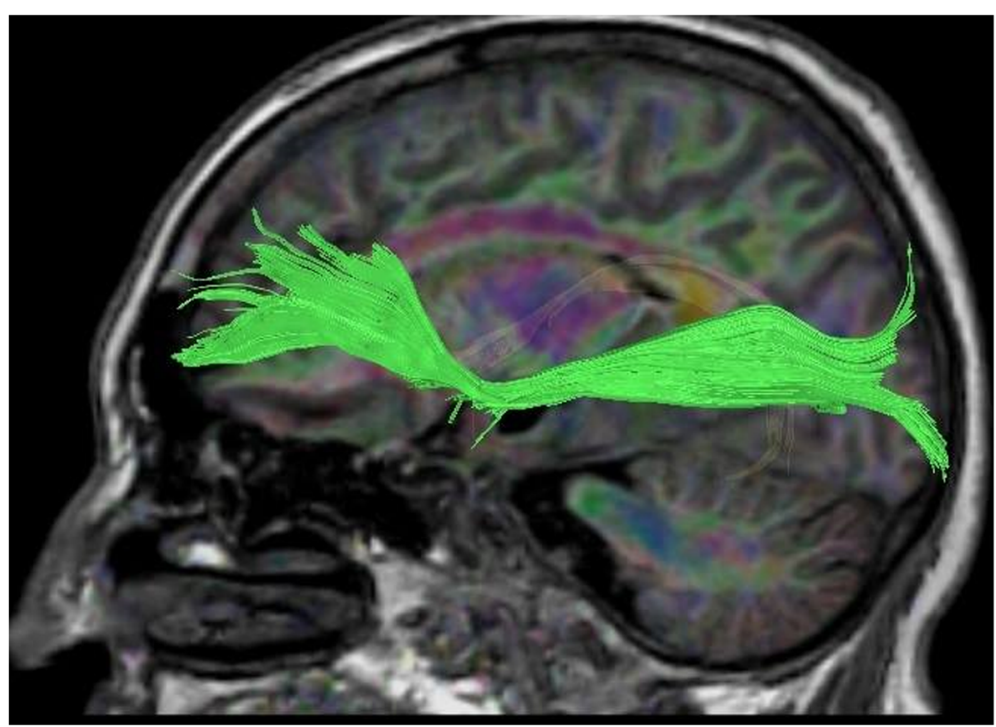

Fig. 2 Sagittal view of the detailed tractography of the right superior longitudinal fasciculus (SLF) in a diabetic subject with mild cognitive impairment. Color coding is included to assist with identification of the fibers in the images. Fractional anisotropy (FA) is reduced $(0.239 \pm 0.106)$ and mean diffusivity is elevated (MD) $(0.986 \pm 0.236)$ 
Table 5 Fractional anisotropy and mean diffusivity at both right and left hemispheres in diabetics with mild cognitive impairment $(n=17)$

\begin{tabular}{lllll}
\hline & Right & Left & $\boldsymbol{t}$ & $\boldsymbol{p}$ \\
\hline FA of selected tracts & & & & \\
SLF FA & $0.40 \pm 0.073$ & $0.38 \pm 0.07$ & 2.033 & 0.059 \\
ILF FA & $0.37 \pm 0.04$ & $0.33 \pm 0.04$ & $7.500^{*}$ & $<0.001^{*}$ \\
UNC FA & $0.39 \pm 0.05$ & $0.34 \pm 0.04$ & $4.761^{*}$ & $<0.001^{*}$ \\
CCS FA & $0.38 \pm 0.04$ & $0.33 \pm 0.03$ & $11.662^{*}$ & $<0.001^{*}$ \\
CCG FA & $0.38 \pm 0.04$ & $0.34 \pm 0.04$ & $11.192^{*}$ & $<0.001^{*}$ \\
MD of selected tracts & & & & \\
SLF MD & $0.79 \pm 0.07$ & $0.83 \pm 0.08$ & $6.601^{*}$ & $<0.006^{*}$ \\
ILF MD & $0.80 \pm 0.04$ & $0.84 \pm 0.05$ & $7.572^{*}$ & $<0.001^{*}$ \\
UNC MD & $0.79 \pm 0.06$ & $0.83 \pm 0.05$ & $5.334^{*}$ & $<0.001^{*}$ \\
CCS MD & $0.79 \pm 0.05$ & $0.82 \pm 0.05$ & $2.545^{*}$ & $0.022^{*}$ \\
CCG MD & $0.79 \pm 0.06$ & $0.82 \pm 0.06$ & $5.508^{*}$ & $<0.001^{*}$ \\
\hline
\end{tabular}

Data was expressed by using (mean $\pm \mathrm{SD}$ ), $t$ Student's $t$ test, $p p$ value for comparing between right and left

* Statistically significant at $p \leq 0.05$

UNC uncinate, SLF superior longitudinal fasciculus, ILF inferior longitudinal fasciculus, CCS corpus callosum splenium, CCG corpus callosum genu, FA

fractional anisotropy, MD mean diffusivity

\section{Discussion}

Many studies have built growing questions about mild cognitive impairment (MCI) in T2DM [3, 23-26]. In our study, $56.7 \%$ of the selected diabetic patients (17 patients) has mild cognitive impairment through assessment by MoCA scale and all control group show normal score. This comes in accordance with Naga Swetha and his colleagues (2017) when their results revealed that $57.3 \%$ of their selected diabetic patients had MCI [27]. In contrast, in many other studies, MCI prevalence was reported in patients with diabetes mellitus to be between 28 and 38\% [28-31]. This difference may be due to different neuropsychological batteries used and most of those studies was done with young adults and exclude those of age more than 60 years. While the mean of our patients age was $(63.57 \pm 2.8)$ years.

In our study, specific cognitive domains of MoCA scale are affected in diabetics with MCI. Orientation, short-term memory, visuospatial/executive functions, language, and attention show significant statistical difference in diabetics with MCI. These findings are in line with those documented by Yue Wang and his colleagues 2015 [32] and Alagiakrishnan and his colleagues (2013) [33]. The cognitive impairment in T2DM is unclear, but

Table 6 Relation between mean values of fractional anisotropy, mean diffusivity and duration of treatment in diabetics $(n=30)$

\begin{tabular}{|c|c|c|c|c|c|}
\hline & & \multicolumn{4}{|c|}{ Duration of treatment (years) } \\
\hline & & $\leq 2(n=10)$ & $>2(n=20)$ & $t$ & $p$ \\
\hline & & Mean \pm SD & Mean \pm SD & & \\
\hline \multirow[t]{2}{*}{ SLF FA } & Right & $0.42 \pm 0.07$ & $0.43 \pm 0.06$ & 0.271 & 0.788 \\
\hline & Left & $0.39 \pm 0.06$ & $0.41 \pm 0.07$ & 1.05 & 0.300 \\
\hline \multirow[t]{2}{*}{ ILF FA } & Right & $0.42 \pm 0.08$ & $0.42 \pm 0.10$ & 0.071 & 0.944 \\
\hline & Left & $0.40 \pm 0.11$ & $0.39 \pm 0.10$ & 0.121 & 0.905 \\
\hline \multirow[t]{2}{*}{ UNC FA } & Right & $0.43 \pm 0.07$ & $0.43 \pm v 0.11$ & 0.126 & 0.901 \\
\hline & Left & $0.40 \pm 0.08$ & $0.39 \pm 0.11$ & 0.353 & 0.749 \\
\hline \multirow[t]{2}{*}{ CCSFA } & Right & $0.43 \pm 0.08$ & $0.44 \pm 0.09$ & 0 & 1.000 \\
\hline & Left & $0.40 \pm 0.09$ & $0.39 \pm 0.11$ & 0.446 & 0.659 \\
\hline \multirow[t]{2}{*}{ CCGFA } & Right & $0.42 \pm 0.08$ & $0.43 \pm 0.09$ & 0.226 & 0.823 \\
\hline & Left & $0.40 \pm 0.09$ & $0.40 \pm 0.11$ & 0.109 & 0.914 \\
\hline \multirow[t]{2}{*}{ SLF MD } & Right & $0.77 \pm 0.07$ & $0.76 \pm 0.06$ & 0.460 & 0.649 \\
\hline & Left & $0.75 \pm 0.08$ & $0.80 \pm 0.09$ & 1.352 & 0.18 \\
\hline \multirow[t]{2}{*}{ ILF MD } & Right & $0.76 \pm 0.04$ & $0.76 \pm 0.08$ & 0.109 & 0.914 \\
\hline & Left & $0.79 \pm 0.07$ & $0.80 \pm 0.10$ & 0.201 & 0.842 \\
\hline \multirow[t]{2}{*}{ UNC MD } & Right & $0.74 \pm 0.06$ & $0.76 \pm 0.09$ & 0.387 & 0.702 \\
\hline & Left & $0.77 \pm 0.06$ & $0.79 \pm 0.09$ & 0.522 & 0.605 \\
\hline \multirow[t]{2}{*}{ CCS MD } & Right & $0.75 \pm 0.05$ & $0.76 \pm 0.07$ & 0.352 & 0.748 \\
\hline & Left & $0.77 \pm 0.06$ & $0.78 \pm 0.08$ & 0.488 & 0.629 \\
\hline \multirow[t]{2}{*}{ CCG MD } & Right & $0.75 \pm 0.05$ & $0.77 \pm 0.06$ & 0.661 & 0.514 \\
\hline & Left & $0.78 \pm 0.07$ & $0.79 \pm 0.07$ & 0.491 & 0.627 \\
\hline
\end{tabular}

$t$ Student's $t$ test, $p p$ value for associated between the three categories, SLF superior longitudinal fasciculus, ILF inferior longitudinal fasciculus, UNC uncinate, CCS corpus callosum splenium, CCG corpus callosum genu, FA fractional anisotropy, MD mean diffusivity 
Table 7 Mean values of fractional anisotropy, mean diffusivity in diabetics according to glycemic control $(n=30)$

\begin{tabular}{|c|c|c|c|c|c|c|}
\hline & & \multicolumn{3}{|l|}{$\mathrm{HbA1c}$} & \multirow[t]{2}{*}{$F$} & \multirow[t]{2}{*}{$p$} \\
\hline & & $\begin{array}{l}\text { Good control }(n=8) \\
\text { Mean } \pm \text { SD }\end{array}$ & $\begin{array}{l}\text { Moderate control }(n=11) \\
\text { Mean } \pm \text { SD }\end{array}$ & $\begin{array}{l}\text { Poor control }(n=11) \\
\text { Mean } \pm \text { SD }\end{array}$ & & \\
\hline \multirow[t]{2}{*}{ SLF FA } & Right & $0.45 \pm 0.05$ & $0.40 \pm 0.09$ & $0.43 \pm 0.55$ & 1.360 & 0.274 \\
\hline & Left & $0.42 \pm 0.04$ & $0.39 \pm 0.08$ & $0.40 \pm 0.06$ & 0.445 & 0.645 \\
\hline \multirow[t]{2}{*}{ ILF FA } & Right & $0.50 \pm 0.09$ & $0.43 \pm 0.08$ & $0.35 \pm 0.02$ & 12.761 & $<0.001^{* *}$ \\
\hline & Left & $0.50 \pm 0.10$ & $0.40 \pm 0.08$ & $0.30 \pm 0.02$ & 17.329 & $<0.001^{* *}$ \\
\hline \multirow[t]{2}{*}{ UNC FA } & Right & $0.50 \pm 0.12$ & $0.43 \pm 0.10$ & $0.37 \pm 0.05$ & 4.655 & $0.018^{* *}$ \\
\hline & Left & $0.49 \pm 0.09$ & $0.38 \pm 0.08$ & $0.33 \pm 0.04$ & 11.676 & $<0.001^{* *}$ \\
\hline \multirow[t]{2}{*}{ CCS FA } & Right & $0.51 \pm 0.07$ & $0.44 \pm 0.08$ & $0.38 \pm 0.03$ & 9.859 & $0.001^{* *}$ \\
\hline & Left & $0.50 \pm 0.10$ & $0.38 \pm 0.08$ & $0.33 \pm 0.03$ & 13.326 & $<0.001^{* *}$ \\
\hline \multirow[t]{2}{*}{ CCG FA } & Right & $0.50 \pm 0.09$ & $0.42 \pm 0.08$ & $0.38 \pm 0.05$ & 6.132 & $0.006^{* *}$ \\
\hline & Left & $0.51 \pm 0.10$ & $0.38 \pm 0.08$ & $0.33 \pm 0.05$ & 12.322 & $<0.001^{* *}$ \\
\hline \multirow[t]{2}{*}{ SLF MD } & Right & $0.72 \pm 0.01$ & $0.80 \pm 0.08$ & $0.76 \pm 0.09$ & 4.627 & $0.01^{*}$ \\
\hline & Left & $0.69 \pm 0.05$ & $0.79 \pm 0.07$ & $0.84 \pm 0.08$ & 9.98 & $0.001^{*}$ \\
\hline \multirow[t]{2}{*}{ ILF MD } & Right & $0.70 \pm 0.08$ & $0.76 \pm 0.05$ & $0.81 \pm 0.02$ & 11.095 & $<0.001^{* *}$ \\
\hline & Left & $0.70 \pm 0.08$ & $0.79 \pm 0.06$ & $0.87 \pm 0.03$ & 20.673 & $<0.001^{* *}$ \\
\hline \multirow[t]{2}{*}{ UNC MD } & Right & $0.68 \pm 0.08$ & $0.73 \pm 0.05$ & $0.82 \pm 0.03$ & 16.769 & $<0.001^{* *}$ \\
\hline & Left & $0.70 \pm 0.08$ & $0.77 \pm 0.06$ & $0.85 \pm 0.01$ & 16.986 & $<0.001^{* *}$ \\
\hline \multirow[t]{2}{*}{ CCS MD } & Right & $0.69 \pm 0.06$ & $0.73 \pm 0.04$ & $0.82 \pm 0.02$ & 23.197 & $<0.001^{* *}$ \\
\hline & Left & $0.70 \pm 0.04$ & $0.78 \pm 0.06$ & $0.83 \pm 0.05$ & 15.354 & $<0.001^{* *}$ \\
\hline \multirow[t]{2}{*}{ CCG MD } & Right & $0.71 \pm 0.02$ & $0.74 \pm 0.04$ & $0.82 \pm 0.03$ & 27.863 & $<0.001^{* *}$ \\
\hline & Left & $0.72 \pm 0.02$ & $0.77 \pm 0.05$ & $0.86 \pm 0.03$ & 35.023 & $<0.001^{* *}$ \\
\hline
\end{tabular}

$F F$ for ANOVA test, $p p$ value for comparing between the different categories

**Highly statistically significant at $p \leq 0.01$

*Statistically significant at $p \leq 0.05$

UNC uncinate, SLF superior longitudinal fasciculus, ILF inferior longitudinal fasciculus, CCS corpus callosum splenium, CCG corpus callosum genu, FA fractional aniostropy, MD mean diffusivity

hyperglycemia, vascular disease, hypoglycemia, insulin resistance, amyloidosis, concomitant hypertension, and depression could play significant roles [34, 35].

In our study, we picked four tracts of white matter to be tested: superior longitudinal fasciculus, inferior longitudinal fasciculus, uncinate fasciculus, and corpus callosum "both genu and splenium." Consistent group differences in mean diffusivity values in the majority of tracts in both hemispheres, indicating that individuals with type 2 diabetes have abnormalities in the microstructure of the white matter.

In our study, fractional anisotropy in diabetic patients with $\mathrm{MCI}$ is highly significantly reduced at all selected tracts at "both right and left sides" than diabetic patients without MCI and controls. Mean diffusivity in diabetic patients with MCI is highly significantly elevated at all selected tracts at "both right and left sides" than diabetic patients without MCI and controls, FA changes had been less prominent. This can be inerpreted by the fact that the diffusion of white matter fibers is increased parallel (axial) and perpendicular (radial), which has a greater effect on the overall MD than on the axial and radial diffusion (FA) ratio.
Most researches showed a widespread decrease in FA or an rise in MD that could not be interpreted by vascular lesion or total brain volume differences [9, 36-38]. The least FA in this study is detected at the splenium of corpus callosum "mainly the left" with mean value 0.33 \pm 0.03 . This is similar to what is found by many studies confirming that corpus callosum may significantly contribute to the rate of cognitive decline [39-42]. In contrast, Zhang and his colleagues (2014) reported increase in MD in whole corpus callosum and superior longitudinal fasciculus related to $\mathrm{MCI}$ in their selected patients with T2DM [43].

In the majority of tracts in both hemisphere, we found significant group variations in MD values suggesting microstructural abnormalities in the white matter in type 2 diabetes patients. Such findings are consistent with previous reports from a type 2 diabetes study by DTI $[9,37]$.

We found that there is significant relation between cognitive decline assessed by MoCA scale and FA measured mainly at left SLF $(p=0.01)$. This matched with Menge and his colleagues who suggested that the FA 
values of the SLF may be used as a clinical marker of cognitive function [44]. Also, Medina and his colleagues (2006) reported that white matter fibers which are deep in the posterior white matter especially the superior longitudinal fasciculus are influenced in patients with $\mathrm{MCI}$ relative to controls [45]. On the other hand, other studies founded no alterations in the corpus callosum of MCI patient [46-48].

We also found that there were more reduced FA and increased MD in the tested white matter tracts in left hemisphere than in the right with statsitical significance found between both hemispheres. This is the same as found by Zhang and his colleagues (2014) in their study [43]. This can be demonstrated by the HAROLD model (Hemispheric Asymmetry Reduction in Older Adults) [49] which claimed that decreases in age-related hemispheric asymmetry compensate the lower prefrontal activity lateralization during cognitive performance in older adults compared to younger ones.

In our study, duration of diabetes is not of statistical relation with the cognitive impairment found among diabetics with MCI. Same results was reported by Reijmer and his colleagues (2013) [9]. In contrast, Rosebud Roberts and his colleagues (2008) [50], Chen and his colleagues (2012) [51], and LIU and his colleagues (2017) [52] founded a statistical relation between MCI and duration of diabetes. The discrepancy in the results may be due to variations in the nature of the study, sources of research subjects, and variations in length or intensity of DM between subjects of research.

In our study, there is a statistical significance between the cognitive impairment and the degree of glycemic. We found that $41.2 \%$ of the diabetics with MCI were of moderate glycemic control with $\mathrm{HbA} 1 \mathrm{c}=7-9 \%$ and $58.8 \%$ had poor glycemic control with HbA1c $>9 \%$. Several studies have shown that HbA1clevel and cognitive function have a very close relationship [3, 23-26, 5361]. In the contrary, other studies founded that there is no significant relation between glycemic control and mild cognitive impairment $[62,63]$. This discrepancy in confirming the relation between the glycemic control and cognitive decline rises from the point that studies which confirmed that point, were conducted mostly in patients above the mean age of 60 years, as our study.

\section{Conclusion}

Mild cognitive impairment is related to T2DM (56.7\%). The integrity of the white matter measured using DTI vary in MCI diabetics compared with non-MCI diabetics. Such changes have major implications on the cognitive function. In left hemisphere, the FA values are statistically more reduced and MD values are statistically more elevated.

\section{Abbreviations}

CCG: Corpus callosum genu; CCS: Corpus callosum splenium; DM: Diabetes mellitus; DTI: Diffusion tensor imaging; FA: Fractional anisotropy; MCl: Mild cognitive impairment; MD: Mean diffusivity; MoCA: Montreal Cognitive Assessment scale; ILF: Inferior longitudinal fasciculus; SLF: Superior longitudinal fasciculus; UNC: Uncinate

\section{Acknowledgements}

Not applicable

\section{Authors' contributions}

OA carried out the study conception and design, participated in its design and coordination, and drafted the manuscript. HT carried out the design of the study, the analysis, and interpretation of data and helped to draft the manuscript. NM participated in the sequence alignment, interpretation of data, and drafting of manuscript. AR carried out the study conception and design, and participated in its design. AH participated by acquisition of data and performed the statistical analysis. All authors read and approved the final manuscript.

\section{Funding}

The authors were responsible for the cost of this study including the design of the study and collection, analysis, and interpretation of data and in writing the manuscript and no funding.

\section{Availability of data and materials}

The data can be publicly available at the Faculty of Medicine, Suez Canal University.

\section{Ethics approval and consent to participate}

The study was approved by the Ethics committee of Suez Canal Faculty of Medicine in 20 January 2016. Committee Number: 2612. An informed written consent was taken from all the participants in the study.

\section{Consent for publication}

Participants signed an informed consent for publication.

\section{Competing interests}

The authors declare that they have no competing interests (financial or nonfinancial).

\section{Author details}

${ }^{1}$ Department of Neurology, Suez Canal University, Ismailia, Egypt.

${ }^{2}$ Department of diagnostic radiology, Suez Canal University, Ismailia, Egypt.

Received: 24 June 2020 Accepted: 28 September 2020

Published online: 11 December 2020

\section{References}

1. Forouhi NG, Wareham NJ. Epidemiology of diabetes. Medicine (United Kingdom). 2019:42(12):698-702.

2. Cheng $G$, Huang C, Deng $H$, Wang $H$. Diabetes as a risk factor for dementia and mild cognitive impairment: a meta-analysis of longitudinal studies. Intern Med J. 2012;42(5):484-91.

3. Cukierman-Yaffe T, Gerstein HC, Williamson JD, Lazar RM, Lovato L, Miller $M E$, et al. Relationship between baseline glycemic control and cognitive function in individuals with type 2 diabetes and other cardiovascular risk factors: the action to control cardiovascular risk in diabetes-memory in diabetes (ACCORD-MIND) trial. Diabetes Care. 2009;32(2):221-6.

4. Arvanitakis Z, Wilson RS, Schneider JA, Bienias JL, Evans DA, Bennett DA. Diabetes mellitus and progression of rigidity and gait disturbance in older persons. Neurology. 2004;63(6):996-1001.

5. Biessels GJ, Kappelle AC, Bravenboer B, Erkelens DW, Gispen WH. Cerebral function in diabetes mellitus. Diabetologia. 1994;37(7):643-50.

6. Ott A, Stolk RP, Van Harskamp F, Pols HA, Hofman A, Breteler MM. Diabetes mellitus and the risk of dementia: The Rotterdam Study. Neurology. 1999; 53(9):1937-42

7. Peila R, Rodriguez BL, Launer $\amalg$. Type 2 diabetes, APOE gene, and the risk for dementia and related pathologies: The Honolulu-Asia Aging Study. Diabetes. 2002;51(4):1256-62. 
8. Bruce DG, Casey GP, Grange V, Clarnette RC, Almeida OP, Foster JK, et al. Cognitive impairment, physical disability and depressive symptoms in older diabetic patients: the Fremantle Cognition in Diabetes Study. Diabetes Res Clin Pract. 2003:61(1):59-67.

9. Reijmer YD, Brundel M, De Bresser J, Kappelle LJ, Leemans A, Biessels GJ, et al. Microstructural white matter abnormalities and cognitive functioning in type 2 diabetes: a diffusion tensor imaging study. Diabetes Care. 2013; 36(1):137-44.

10. Manschot SM, Brands AM, van der Grond J, Kessels RP, Algra A, Kappelle LJ, et al. Brain magnetic resonance imaging correlates of impaired cognition in patients with type 2 diabetes. Diabetes. 2006;55(4):1106-13.

11. Basser PJ, Jones DK. Diffusion-tensor MRI: theory, experimental design and data analysis-a technical review. NMR in Biomedicine: An International Journal Devoted to the Development and Application of Magnetic Resonance In Vivo. 2002;15(7-8):456-67.

12. Le Bihan D, Mangin JF, Poupon C, Clark CA, Pappata S, Molko N, et al. Diffusion tensor imaging: concepts and applications. Journal of Magnetic Resonance Imaging: An Official Journal of the International Society for Magnetic Resonance in Medicine. 2001:13(4):534-46.

13. Li H, Liang Y, Chen K, Li X, Shu N, Zhang Z, et al. Different patterns of white matter disruption among amnestic mild cognitive impairment subtypes: relationship with neuropsychological performance. J Alzheimers Dis. 2013; 36(2):365-76.

14. Stahl R, Dietrich O, Teipel SJ, Hampel H, Reiser MF, Schoenberg SO. White matter damage in Alzheimer disease and mild cognitive impairment: assessment with diffusion-tensor MR imaging and parallel imaging techniques. Radiology. 2007;243(2):483-92.

15. American Diabetes Association. Diagnosis and classification of diabetes mellitus. Diabetes care. 2010; 33(Supplement 1):S62-9.

16. Khaw KT, Wareham N, Bingham S, Luben R, Welch A, Day N. Preliminary communication: glycated hemoglobin, diabetes, and incident colorectal cancer in men and women: a prospective analysis from the European prospective investigation into Cancer-Norfolk Study. Cancer Epidemiology and Prevention Biomarkers. 2004:13(6):915-9.

17. American Diabetes Association. Standards of medical care in diabetes--2014. Diabetes care. 2014; 37:S14

18. Rahman T, El Gaafary MM. Montreal Cognitive Assessment Arabic version: reliability and validity prevalence of mild cognitive impairment among elderly attending geriatric clubs in Cairo. Geriatr Gerontol Int. 2009;9(1):5461.

19. Nasreddine ZS, Phillips NA, Bédirian V, Charbonneau S, Whitehead V, Collin I, et al. The Montreal Cognitive Assessment, MoCA: A brief screening tool for mild cognitive impairment. J Am Geriatr Soc. 2005;53(4):695-9.

20. O'Sullivan M, Morris RG, Huckstep B, Jones DK, Williams SC, Markus HS. Diffusion tensor MRI correlates with executive dysfunction in patients with ischaemic leukoaraiosis. J Neurol Neurosurg Psychiatry. 2004;75(3):441-7.

21. Ibrahim A, Gomaa M, Sakr H, Elzaher Y. Role of diffusion tensor imaging in characterization and preoperative planning of brain neoplasms. The Egyptian Journal of Radiology and Nuclear Medicine. 2013:44(2):297-307.

22. Krzywinski M, Altman N. Significance, $P$ values and t-tests: the $P$ value reported by tests is a probabilistic significance, not a biological one. Nat Methods. 2013;10(11):1041-3.

23. Yaffe K, Falvey C, Hamilton N, Schwartz AV, Simonsick EM, Satterfield S, et al. Diabetes, glucose control, and 9-year cognitive decline among older adults without dementia. Arch Neurol. 2012;69(9):1170-5.

24. Meneilly GS, Cheung E, Tessier D, Yakura C, Tuokko H. The effect of improved glycemic control on cognitive functions in the elderly patient with diabetes. J Gerontol. 1993;48(4):M117-21.

25. Biessels GJ, Staekenborg S, Brunner E, Brayne C, Scheltens P. Risk of dementia in diabetes mellitus: a systematic review. The Lancet Neurology. 2006;5(1):64-74

26. Cukierman T, Gerstein HC, Williamson JD. Cognitive decline and dementia in diabetes - systematic overview of prospective observational studies. Diabetologia. 2005;48(12):2460-9.

27. Naga Swetha MS, Kumar VA. Study of Risk Factors of Mild Cognitive Impairment in Patients with Type 2 Diabetes Mellitus. Int J Sci Res Publ. 2017;7(11):672

28. Luchsinger JA, Reitz C, Patel B, Tang MX, Manly JJ, Mayeux R. Relation of diabetes to mild cognitive impairment. Arch Neurol. 2007;64(4):570-5.

29. Yamazaki Y, Miwa T, Sakurai H, Hanyu H, Iwamoto T, Odawara M. Clinical backgrounds and morbidity of cognitive impairment in elderly diabetic patients. Endocr J. 2011;58(2):109-15.
30. Gorska-Ciebiada M, Saryusz-Wolska M, Ciebiada M, Loba J. Mild cognitive impairment and depressive symptoms in elderly patients with diabetes: prevalence, risk factors, and comorbidity. J Diabetes Res. 2014;2014.

31. Roy S, Kim N, Desai A, Komaragiri M, Baxi N, Jassil N, et al. Cognitive function and control of type 2 diabetes mellitus in young adults. N Am J Med Sci. 2015;7(5):1-7.

32. Wang $Y, X u X Y$, Feng $C H$, Li YL, Ge X, Zong GL, et al. Patients with type 2 diabetes exhibit cognitive impairment with changes of metabolite concentration in the left hippocampus. Metab Brain Dis. 2015;30(4):1027-34.

33. Alagiakrishnan $K$, Zhao N, Mereu L, Senior P, Senthilselvan A. Montreal Cognitive Assessment is superior to Standardized Mini-Mental Status Exam in detecting mild cognitive impairment in the middle-aged and elderly patients with type 2 diabetes mellitus. Biomed Res Int. 2013;2013.

34. Kodl CT, Seaquist ER. Cognitive dysfunction and diabetes mellitus. Endocr Rev. 2008:29(4):494-511.

35. Cosway R, Strachan MW, Dougall A, Frier BM, Deary IJ. Cognitive function and information processing in type 2 diabetes. Diabet Med. 2001;18(10): 803-10

36. Falvey CM, Rosano C, Simonsick EM, Harris T, Strotmeyer ES, Satterfield S, et al. Macro-and microstructural magnetic resonance imaging indices associated with diabetes among community-dwelling older adults. Diabetes Care. 2013;36(3):677-82.

37. Hsu JL, Chen YL, Leu JG, Jaw FS, Lee CH, Tsai YF, et al. Microstructural white matter abnormalities in type 2 diabetes mellitus: a diffusion tensor imaging study. Neuroimage. 2012;59(2):1098-105.

38. Yau PL, Javier D, Tsui W, Sweat V, Bruehl H, Borod JC, et al. Emotional and neutral declarative memory impairments and associated white matter microstructural abnormalities in adults with type 2 diabetes. Psychiatry Res Neuroimaging. 2009;174(3):223-30.

39. Dimitra S, Verganelakis DA, Gotsis E, Toulas P, Papatriantafillou J, Karageorgiou C, et al. Diffusion tensor imaging (DTI) in the detection of white matter lesions in patients with mild cognitive impairment (MCI). Acta Neurol Belg. 2013;113(4):441-51.

40. Rose SE, Chen F, Chalk JB, Zelaya FO, Strugnell WE, Benson M, et al. Loss of connectivity in Alzheimer's disease: an evaluation of white matter tract integrity with colour coded MR diffusion tensor imaging. J Neurol Neurosurg Psychiatry. 2000;69(4):528-30.

41. Cho H, Yang DW, Shon YM, Kim BS, Kim YI, Choi YB, et al. Abnormal integrity of corticocortical tracts in mild cognitive impairment: a diffusion tensor imaging study. J Korean Med Sci. 2008;23(3):477-83.

42. Takahashi S, Yonezawa H, Takahashi J, Kudo M, Inoue T, Tohgi H. Selective reduction of diffusion anisotropy in white matter of Alzheimer disease brains measured by 3.0 Tesla magnetic resonance imaging. Neurosci Lett. 2002;332(1):45-8.

43. Zhang J, Wang Y, Wang J, Zhou X, Shu N, Wang Y, et al. White matter integrity disruptions associated with cognitive impairments in type 2 diabetic patients. Diabetes. 2014;63(11):3596-605.

44. Meng JZ, Guo LW, Cheng H, Chen YJ, Fang L, Qi M, et al. Correlation between cognitive function and the association fibers in patients with Alzheimer's disease using diffusion tensor imaging. J Clin Neurosci. 2012; 9(12):1659-63.

45. Medina D. deToledo-Morrell L, Urresta F, Gabrieli JD, Moseley M, Fleischman $D$, et al. White matter changes in mild cognitive impairment and AD: a diffusion tensor imaging study. Neurobiol Aging. 2006;27(5):663-72.

46. Petersen RC, Doody R, Kurz A, Mohs RC, Morris JC, Rabins PV, Ritchie K, Rossor M, Thal L, Winblad B. Current concepts in mild cognitive impairment. Arch Neurol. 2001;58(12):1985-92.

47. Zhang Y, Schuff N, Jahng GH, Bayne W, Mori S, Schad L, et al. Diffusion tensor imaging of cingulum fibers in mild cognitive impairment and Alzheimer disease. Neurology. 2007;68(1):13-9.

48. Rose SE, McMahon KL, Janke AL, O'Dowd B, de Zubicaray G, Strudwick MW, et al. Diffusion indices on magnetic resonance imaging and neuropsychological performance in amnestic mild cognitive impairment. J Neurol Neurosurg Psychiatry. 2006;77(10):1122-8.

49. Cabeza R. Hemispheric asymmetry reduction in older adults: the HAROLD model. Psychol Aging. 2002;17(1):85.

50. Roberts RO, Geda YE, Knopman DS, Christianson TJ, Pankratz VS, Boeve BF, et al. Association of duration and severity of diabetes mellitus with mild cognitive impairment. Arch Neurol. 2008;65(8):1066-73.

51. Chen RH, Jiang XZ, Zhao XH, Qin YL, Gu Z, Gu PL, et al. Risk factors of mild cognitive impairment in middle aged patients with type 2 diabetes: $A$ cross-section study. In Annales d'endocrinologie. 2012;73(3):208-12. 
52. Liu ZQ, Zhang MX, Wang J, Ding N. Analysis of correlation between the mild cognitive impairment $(\mathrm{MCl})$ and level of adiponectin in elderly patients with type 2 diabetes mellitus (T2DM). Eur Rev Med Pharmacol Sci. 2017; 21(23):5471-7.

53. Crane PK, Walker R, Hubbard RA, Li G, Nathan DM, Zheng H, et al. Glucose levels and risk of dementia. N Engl J Med. 2013;369(6):540-8.

54. Sanz CM, Ruidavets JB, Bongard V, Marquié JC, Hanaire H, Ferrières J, Andrieu S. Relationship between markers of insulin resistance, markers of adiposity, $\mathrm{HbA1c}$, and cognitive functions in a middle-aged populationbased sample: the MONA LISA study. Diabetes Care. 2013;36(6):1512-21.

55. Umegaki H, Kawamura T, Mogi N, Umemura T, Kanai A, Sano T. Glucose control levels, ischaemic brain lesions, and hyperinsulinaemia were associated with cognitive dysfunction in diabetic elderly. Age Ageing. 2008; 37(4):458-61.

56. Shorr Rl, De Rekeneire N, Resnick HE, Yaffe K. Glycemia and cognitive function in older adults using glucose-lowering drugs. J Nutr Health Aging. 2006;10(4):297.

57. Kanaya AM, Barrett-Connor E, Gildengorin G, Yaffe K. Change in cognitive function by glucose tolerance status in older adults: a 4-year prospective study of the Rancho Bernardo study cohort. Arch Intern Med. 2004;164(12): 1327-33.

58. Launer LJ, Miller ME, Williamson JD, Lazar RM, Gerstein HC, Murray AM, et al Effects of intensive glucose lowering on brain structure and function in people with type 2 diabetes (ACCORD MIND): a randomised open-label substudy. The Lancet Neurology. 2011;10(11):969-77.

59. Nguyen HT, Grzywacz JG, Arcury TA, Chapman C, Kirk JK, Ip EH, et al. Linking glycemic control and executive function in rural older adults with diabetes mellitus. J Am Geriatr Soc. 2010;58(6):1123-7.

60. Yaffe K, Blackwell T, Whitmer RA, Krueger K, Barrett-Connor E. Glycosylated hemoglobin level and development of mild cognitive impairment or dementia in older women. J Nutr Health Aging. 2006;10(4):293-5.

61. Zhang YW, Zhang JQ, Liu C, Wei P, Zhang X, Yuan QY, et al. Memory dysfunction in type 2 diabetes mellitus correlates with reduced hippocampal CA1 and subiculum volumes. Chin Med J. 2015;128(4):465-71.

62. Ikonomovic MD, Klunk WE, Abrahamson EE, Mathis CA, Price JC, Tsopelas $N D$, et al. Post-mortem correlates of in vivo PiB-PET amyloid imaging in a typical case of Alzheimer's disease. Brain. 2008;131(6):1630-45.

63. Van den Berg E, Reijmer YD, De Bresser J, Kessels RP, Kappelle LU, Biessels $G J$, et al. A 4 year follow-up study of cognitive functioning in patients with type 2 diabetes mellitus. Diabetologia. 2010;53(1):58-65.

\section{Publisher's Note}

Springer Nature remains neutral with regard to jurisdictional claims in published maps and institutional affiliations.

\section{Submit your manuscript to a SpringerOpen ${ }^{\circ}$ journal and benefit from:}

- Convenient online submission

- Rigorous peer review

- Open access: articles freely available online

- High visibility within the field

- Retaining the copyright to your article

Submit your next manuscript at $\boldsymbol{\nabla}$ springeropen.com 